\title{
CORRESPONDENCE
}

\author{
Diet and Congenital Defects \\ J. Lorber, F.R.C.P.; K. M. Laurence, \\ M.R.C.PATH. $\ldots \ldots \ldots \ldots \ldots \ldots \ldots \ldots \ldots, 46$
}

Minors and Medical Experiments

A. M. W. Porter, M.D..............46

Treatment of Status Asthmaticus

K. N. V. Palmer, F.R.C.P.; H. G. McGregor M.D.; M. Marshall, F.F.A.R.C.S.; L. O Mountford, F.F.A.R.C.S.; A. M. Hewlett, M.B. and D. C. White, F.F.A.R.C.S. . . . . . . 47

Infertility after the Pill

F. T. B. Lovegrove, M.B...........48

\section{Management of Early Breast Cancer}

D. K. Sambrook, F.R.C.S. . . . . . . . . .48

Tragic Dilemma

D. E. Ford, M.B.; G. C. W. Sharpe, M.R.C.G.P.,

and others; S. L. H. Smith, D.T.M. \& H...... 48
Barbiturates and Methyldopa Metabolism

M. Kristensen, M.D., and others........49

How Many Acute Beds Do We Really Need ?

J. W. Paulley, F.R.C.P., and J. P. Hughes,

M.R.C.P. . . . . . . . . . . . . . . . .49

Graphic Records in Labour

M. Notelovitz, M.D................50

X-ray-negative Dyspepsia in General

Practice

L. Ratoff, M.R.C.G.P. . . . . . . . . . . . . 50

Coronary Artery Disease

A. Elkeles, M.D.................5

Contraception for the Needy

C. J. Schilling, M.R.C.P.; S. C. Rowlands....51

Family Planning Payments

M. V. Smith, D.P.H. . . . . . . . . . 51

Wax in the Ear

I. $H$. J. Bourne, M.B. $\ldots \ldots \ldots \ldots \ldots \ldots .51$
Uganda Asians

R. S. K. Essame, M.R.C.G.P., and R.C.

MacLeod, M.D...................52

Twenty Copies, Please

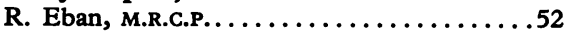

Making Hospital Geriatrics Work

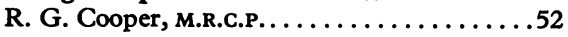

Polio Vaccination and Tuberculin Test

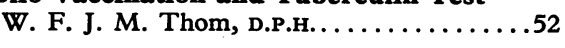

Pathologists in Distress

A. G. Marshall, F.R.C.PATH. . . . . . . . . 52

London Allowance for Hospital Doctors

M. A. Arif, M.B................53

Nothing New under the Sun

K. E. Jolles, M.R.c.s. . . . . . . . . . . . 53

\section{M.A.D.R.A.S.}

H. C. Davis, F.D.S., and J. M. Clubb,

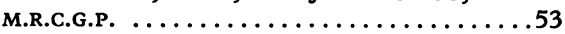

\section{Diet and Congenital Defects}

SIR,-Your leading article on diet and congenital defects (23 December, p. 684) gives a very fair and considered assessment of the possible role potatoes may or may not play in the aetiology of anencephalus and spina bifida. Perhaps one might add at least two major reasons why potatoes or blight in potatoes are not likely to be either the sole cause or the major cause in the aetiology of these disorders.

One is that the occurrence of these disorders in twins is very uncommon-for example, when one twin is affected the other is usually normal. There are at least 10 normal twins to one abnormal. It is difficult to believe that potato blight could effect one twin and not the other.

The second point is that even if potatoes or blight were responsible in some way, they would still have to act through another agency, as otherwise the incidence of spina bifida in our population would be much higher. If potato blight were a straight poison, like thalidomide, one would expect a substantially higher incidence than four per 1,000 (if the two disorders are combined).

Your article concluded with the sentence: "Until a trial or other appropriate work has provided more conclusive evidence, the theory can be explained to women with an affected child who are planning another pregnancy so that if they wish they can avoid potatoes completely until they become pregnant and the fetus is at least two months old." Your readers may like to know that such a trial is in progress through the Association of Spina Bifida and Hydrocephalus on exactly the basis that your last sentence suggests. I should be very glad to hear of any parents who already have a child with spina bifida, who wish to have other children, and who would be willing to take part in the trial, which is fully explained in the latest issue of the association's journal, Link.-I am, etc.

The Children's Hospital,

JOHN LORBER Western Bank, Sheffield

SIR,-Your leading article about the hypothesis linking potato consumption with neural tube malformation (23 December, $p$. 684) was most welcome, for it may help to bring some sanity to the subject. It has been somewhat worrying that this theory has been given so much publicity in the scientific and medical press, as well as the mass media, often in highly emotional and exaggerated terms, with claims of a relationship which, even if it exists, is most unlikely to be as direct as Renwick ${ }^{1}$ claims.

A climate of opinion is being created in the general public which makes it very difficult to launch a properly randomized and controlled trial of potato avoidance in susceptible women going in for a further pregnancy who have previously had a child with spina bifida or anencephaly. Such a trial is probably the only way in which this theory could be tested out quickly in man and could probably be completed in less than two years if carried out on a multicentre basis.

What is even more worrying is that in the meantime some women who have avoided pregnancy for fear of a recurrence might embark upon a pregnancy in the belief that potato avoidance will eliminate that risk.-I am, etc.,

K. M. LAURENCE

Welsh National School of Medicine,

Department of Child Health,

Llandough Hospital,

Penarth, Glamorgan

1 Renwick, J. H., New Scientist, 1972, 56, 277.

\section{Minors and Medical Experiments}

SIR,-The first observed symptom of sudden and unexpected death in infancy (S.U.D.I.) is death. This makes it not only a unique syndrome in medical practice, but also hampers efforts to define classification and aetiology. There is one approach to the problem which has been hitherto neglected. If one assumes that both genetic and environmental factors are involved, then the primary relatives of the victim are a group who share half the genes and usually the same environment as the dead infant. These relatives may be subjected to tests and challenges which ideally would have been made on the victim if the fatal condition could have been anticipated. The primary relatives may be used, in fact, as substitute subjects. In pursuit of this principle I plan a study which involves taking samples of blood from each of the primary relatives of a victim before and after a test feed of reconstituted cow's milk. Valuable information would be lost if siblings who were minors had to be excluded.

I was surprised to learn that venesection of minors, even with the consent of parents, might be unethical, and the Medical $R e-$ 
search Council was quoted as the authority. likelihood of this is balanced by the gravity I accordingly wrote to the M.R.C. and re- of the issue.-I am, etc., ceived in return a copy of their booklet "Responsibility in Investigations on Human Subjects," reprinted from their report for 1962-3.1 In this I found little for my comfort. The pertinent sentence is: "In the strict view of the law parents and guardians of minors cannot give consent on their behalf to any procedures which are of no particular benefit to them and which may carry some risk of harm." The M.R.C. have kindly obtained a further opinion from their legal advisers, who confirm that the general position has not changed since the statement was originally published in 1964 . I believe that this ruling has shortcomings when applied to a particular situation such as my proposed study. Further, it contravenes the principle that all human beings have an obligation to the society which nurtures them and that this obligation is incurred the moment we are born and not just when the age of majority is reached.

I have completed a small attitude study to test lay and professional opinion about this problem. The following form was compiled:

This is a problem of medical ethics and your comments would be welcomed.

An infant dies suddenly at home of a mysterious disorder. A doctor doing research into the disorder wishes to take two samples of blood from each near relative-mother, father, brothers, and sisters. The procedure is much the same as taking a sample of blood from a mother at her first antenatal attendance.

The taking of blood from the brothers and sisters of the dead infant cannot benefit them personally but may benefit research into the cause of the baby's death.

Some persons believe that a doctor in such circumstances should not take blood from children even if the parents agree.

Others think that the parents have the right to decide and that, with their permission, the doctor may take blood.

Which opinion do you hold? Please ring the reply which most closely matches your opinion.

A. That the doctor may take blood from the children.

B. That he may not take blood from the children.

C. Uncertain.

This form was presented by myself without comment to 10 doctors (two house surgeons; a pathologist; a physician; a geriatrician; an epidemiologist; a surgeon; and three general practitioners) and all but one (a general practitioner) ringed choice A. A professional market researcher also showed the form to 10 lay persons in the course of her other duties (three male manual workers; two male non-manual workers; one female manual worker; and four female nonmanual workers). All ringed choice A. By a coincidence the woman manual worker had lost an infant suddenly and unexpectedly and she was emphatic in her choice of alternative $\mathbf{A}$.

It would seem therefore, that public opinion and the law are at variance, and this must always be a cause for concern. While the position remains unchanged legitimate research in this country may be hampered. In the case of my own proposed study I feel justified in proceeding. Familial aggregation exists in S.U.D.I. and it could be argued that the study might benefit eventually the sibling subjects in a manner which cannot be closely defined at this moment. The un-
Camberley, Surrey

Alan Porter

Medical Research Council, Report for the Year

\section{Treatment of Status Asthmaticus}

SIR,-Your leading article (9 December, p. 563) gives a valuable account of the treatment of this common and potentially lethal medical emergency. I disagree, however, with your statement that physiotherapy has no place in the treatment of this condition. There are, admittedly, some patients who are too ill and exhausted to co-operate in this treatment and these frequently require assisted ventilation soon after admission to hospital. Nevertheless, physiotherapy-that is to say, frequent assisted coughing with vibratory percussion to the lung bases rather than postural drainage-can, in my experience and that of others, ${ }^{1}$ be given with much benefit to many patients in status asthmaticus, even to those with hypercapnia. Indeed, hypercapnia is invariably associated with the retention of large amounts of viscid bronchial secretion, and when this is coughed up the raised arterial carbon dioxide tension falls, hypoxaemia improves, and the need for assisted ventilation is often averted.

The bronchial secretion is characteristically highly viscid in severe asthma. Bromhexine reduces sputum viscosity ${ }^{2}$ and I always give this parenterally or by mouth in addition to physiotherapy.-I am, etc.,

K. N. V. PALMER versity of Aberdeen

1 Rebuck, A. S., and Read, J., American fournal 2 Hamilton, W. F. D., Palmer, K. N. V., and Gent M., British Medical fournal, 1970, 3, 260

SIR,-Your excellent leading article on status asthmaticus (9 December, p. 563) is one of a spate that have appeared in various journals recently. There are three points of general interest, however, that have not been made enough of:

(1) Status asthmaticus is almost invariably overtreated in hospital. Visit any ward you fancy and you will find the treatment sheet, after a couple of days, crammed back and front, plus a handful of continuation sheets, with drugs prescribed, countermanded, replaced, substituted, reinstituted, added to, as well as overlooked. Beneath this lies the drugged, sedated, and tranquillized remnants of the patient. Since modern medical treatment is a team matter, the team being a shifting population of clinicians of various ages whose on-duty and off-duty rotas are continually in flux, the team must. at the outset decide collectively on a regime and agree to make no modification of it without reference to the team leader.

(2) The complaint of asthma and its "status" variant is a very individual affair, and chronic asthmatics of several years' standing often know more about their asthma, and the drugs that help them as individuals, than some clinicians. They arrive in hospital with their drugs, which they have learnt from experience to regard as sheet anchors, and it is a mistake to deny possession of them unceremoniously as is sometimes done. A close watch can easily be
Department of Medicine, maintained on them and, if necessary, their use temporarily discouraged with tact on the grounds that it conflicts with the hospital regimen. This may avoid forfeiting the confidence of an often highly intelligent patient at a time of severe anxiety and alarm.

(3) Sedation, in the preintubation phase while respiration is spontaneous, is not necessarily to be denigrated "because of the depressant action of all hypnotics on respiration." Some have a less depressant effect on respiration than others and are not only reasonable risks, but an essential part of treatment. Asthmatics often have a wide knowledge of which are suitable and why some are not. Once the $\mathrm{PaO}_{2}$ falls below the critical level of $50 \mathrm{~mm} \mathrm{Hg}$ and intubation is obligatory the matter of sedation becomes much simpler and less controversial.-I am, etc.,

Hove, Sussex

H. G. MCGREGOR

SIR,-I would like to make three comments on your leading article (9 December, p. 563).

(1) You do not emphasize the severity of dehydration that may be present. Patients may be 1-3 1. in deficit. Replacement should be rapid and controlled by central venous pressure measurements. Hypovolaemic patients withstand positive pressure breathing very badly, and fluid replacement is particularly urgent when cardiac output drops in response to mechanical ventilation. Replacement should be with normal saline, since most of the loss has been as sweat. Inadequate sodium replacement produces a hypotonic plasma which in turn can produce a fatal cerebral oedema.

(2) Formal bronchial lavage may be hazardous. Frequent endotracheal installations of saline followed by suction will clear mucous plugs as effectively as bronchoscopic lavage and is to be preferred. Adequate moistening of the inspissated bronchial secretions is an essential part of active treatment.

(3) Patients in status asthmaticus are liable to considerable variations in compliance. If resistance to inflation increases, a powerful volume-cycled ventilator may rupture mediastinal alveoli unless the machine has a properly working and properly adjusted blow-off valve. Machines less powerful but with a controllable inflation rate may sometimes give better ventilation. A pressure-cycled machine may also rupture by overinflation if an increase in compliance is not matched by a downward adjustment of the inflation pressure. Choosing and adjusting ventilators for asthmatics can be more difficult and time-consuming than your short statement suggests.-I am, etc.,

MERLIN Marshali

Newcastle General Hospital,

Newcastle upon Tyne

SIR,-I would like to make two points in relation to your most excellent leading article (9 December, p. 563).

Advising massive dosage of corticosteroids, you state that "it may be several hours before the airways obstruction begins to subside." This can be a crucial or even fatal period. As an anaesthetist, one is aware of the value of that much-despised drug, ether, in relation to asthmatic patients. Status asthmaticus, whatever the cause, is characterized by extreme constriction of the bron- 